\title{
SOBRE TRILEMAS Y TRILEROS. POR QUÉ LA IDEOLOGÍA ES COSA DE TRES $Y$ LAS EMOCIONES AYUDAN A GESTIONAR LAS DISTINTAS OPCIONES SOBRE LA IDEA DE IGUALDAD
}

\author{
On trilemmas and tricksters. Why ideology is \\ a three-way thing and emotions help to manage \\ different options regarding the idea of equality
}

\author{
CARMELO MORENO \\ Universidad del País Vasco (UPV-EHU) \\ carmelo.moreno@ehu.eus
}

Cómo citar/Citation

Moreno, C. (2017).

Sobre trilemas y trileros. Por qué la ideología es cosa de tres y las emociones ayudan a gestionar las distintas opciones sobre la idea de igualdad.

Revista de Estudios Políticos, 176, 309-339. doi: https://doi.org/10.18042/cepc/rep.176.10

Resumen

La ideología política suele analizarse en torno a la polaridad del eje izquierdaderecha. Esta forma racional y simplificada de ordenar las diferentes alternativas ideológicas sobre la acción política tiene una serie de presupuestos implícitos que, de forma cada vez más evidente, generan más problemas que soluciones a la hora de entender cómo funciona realmente la ideología en nuestras sociedades modernas. Frente a este modelo bipolar, excluyente y reduccionista, este texto plantea las ventajas de analizar la ideología de una forma más plural, trilemáticamente, en torno a tres ejes que se complementan y compiten entre sí de forma entrecruzada: conservadurismo $v$ s. liberalismo vs. socialismo. Esta situación trilemática nos permite analizar la ideología no mediante argumentos de racionalidad política (centrados en la idea de congruencia de uno frente a otro) sino mediante argumentos basados en las emociones, donde la ambigüedad y los sentimientos cruzados juegan un papel mucho más relevante. Un ejemplo de esta situación trilemática se observa en las distintas opciones ideológicas que existen a la hora de abordar, en términos teóricos y prácticos, un concepto como la igualdad. 


\title{
Palabras clave
}

Teoría política; izquierda; derecha; ideología; emociones; igualdad.

\begin{abstract}
Political ideology is often analyzed around the dichotomy of the left-right distinction. This rational and simplified way of ordering the different ideological alternatives to political action has a series of implicit presuppositions that, in an increasingly evident way, generates more problems than solutions when it comes to understanding how ideology really works in modern societies. In opposition to this dichotomous, exclusionary and reductionist model, this text raises the advantages of analyzing ideology in a more plural tripartite way, around three axes that both complement each other and involveoverlapping dimensions of contestation: conservatism vs. liberalism vs. socialism. This reformulation of political ideology as a trilemma allows us to analyze it not through arguments of political rationality (centered on the idea of congruence of one against another) but through arguments based on emotions, where ambiguity and mixed feelings play a much more relevant role. An example of this trilemma can be seen in the different ideological options that exist when it comes to approaching, in theoretical and practical terms, a concept such as equality from conservative, liberal and socialist perspectives.
\end{abstract}

\section{Keywords}

Political theory; left; right; ideology; emotions; equality. 


\section{SUMARIO}

I. INTRODUCCIÓN. II. JOHN M. KEYNES Y FRIEDRICH HAYEK: LA EXTRAÑA PAREJA. III. DEL TRIÁNGULO ISÓSCELES A LA RECTA SOLO HAY UN PASO. IV. LA IDEOLOGÍA ES COSA DE TRES. V. LAS TRES CARAS IDEOLÓGICAS DE LA IGUALDAD. VI. IGUALDAD, IDEOLOGÍAS Y EMOCIONES. UNA PROPUESTA DE ANÁLISIS. BIBLIOGRAFÍA.

\section{INTRODUCCIÓN}

El eje izquierda-derecha explica la articulación ideológica en las sociedades modernas al menos desde la Revolución francesa a finales del siglo XVIII. Como explica Jean A. Laponce en su obra magna Right and Left (1981), esta poderosa "metáfora» ha tenido un especial atractivo y gran persistencia, en distintos países y épocas, como método para obtener una eficaz topografía de las percepciones políticas de los ciudadanos, de sus partidos políticos y de la dinámica electoral. Sin embargo, la principal razón heurística que ha guiado esta forma de aproximarse al mundo de la ideología no es otra que la necesidad práctica, esto es, reducir la complejidad analítica mediante una categorización dual entre dos extremos polarizados que articulan de manera "básica y segura» (Laponce, 1981: 17) las preferencias ideológicas. Es verdad que este esquema binario de las ideologías ha sido matizado a través de un contínuum, esto es, a través de una escala que permite reconocer la existencia de un "tercer elemento» (ibid.: 27) intermedio, generalmente conocido como el centro ideológico. Sin embargo, este elemento suele ser visto como algo que está dentro, y no fuera, de la polaridad izquierdaderecha (Medina, 2015).

No hay que escarbar mucho para detectar que esta forma diádica de entender la ideología política, a pesar de su apariencia práctica y funcional, es bastante cuestionable. Las clasificaciones no duales de la ideología han sido usadas por autores clásicos como Hegel, Marx, Comte, Weber o Freud (Laponce, 1981: 14-15) o más recientes como Albert Hirschman (Laponce, 1974) o Michael Freeden (1996). Pero hay algo más. Autores como Herbert Kitschelt ya han advertido hace décadas que el viejo eje derecha-izquerda para organizar las preferencias de políticas distributivas ha dejado paso a nuevos ejes, como el eje liberal-autoritario (Kitschelt, 1994) que permite encontrar nuevos electores que combinan «preferencias de distribución 
económica derechistas y orientaciones socioculturales liberales» (Kitschelt, 2004: 19) y, por otro lado, permite entender la radicalización de muchos votantes, especialmente de la "nueva derecha», contrarios a la inmigración y en defensa de valores tradicionales (Kitschelt, 1990, 1995). En este mismo sentido, Hooghe et al. (2002) han construido un interesante eje llamado GAL-TAN (partidos verdes, alternativos y libertarios $v$ s. partidos tradicionales, autoritarios y nacionalistas) que, en un tema como el proceso de construcción europea, demuestra ser mejor que el eje izquierda-derecha en un sentido muy importante: permite observar que, por un lado, los partidos de extrema derecha y de extrema izquierda comparten una misma noción ideológica «antiliberal» sobre el proceso de integración en la UE mientras que, por el otro lado, los partidos moderados se muestran favorables al mismo. Términos como izquierda y derecha, vistos como «recíprocamente exclusivos y conjuntamente exhaustivos» (Bobbio, 1995), distorsionan la capacidad para entender en qué consiste realmente la ideología política moderna, si olvidamos que las preferencias ideológicas admiten hoy mixturas ideológicas y unas concomitancias entre los extremos de izquierda y derecha (Ignazi, 2003) contra las posiciones liberales moderadas que ocupaban el centro de la clásica escala ideológica.

En realidad, el eje ideológico izquierda-derecha es una simplificación que funciona analíticamente cuando en un determinado espacio político se asumen implícitamente como naturales dos supuestos que, en realidad, no lo son: i) las comunidades políticas son más o menos homogéneas en términos de nacionalidad comunitaria y ii) las cuestiones de política exterior no afectan a la dinámica política interior de esa comunidad. En la medida que la política se entiende como una burbuja doméstica unitaria que integra las dimensiones políticas en una matriz estatal-nacional, el eje izquierda-derecha sí permite que el sistema ideológico de un país se ordene con sencillez y las diferencias ideológicas se relacionen de manera más o menos centrípeta dentro de ese contínuum. Sin embargo, lo que realmente sucede en la vida política de los Estados democráticos modernos es que esta burbuja doméstica unitaria, si es que ha existido alguna vez, cada vez funciona menos. Básicamente, por dos cuestiones: por un lado, porque la homogeneidad estatal-nacional es un bien cada vez más escaso, sobre todo en países multinacionales o con elevada diversidad étnica debido a la inmigración (Alonso y Claro de Fonseca, 2012); por otro lado, porque la transnacionalización de la agenda política es un asunto cada vez más extendido, como ocurre con la globalización económica, el ecologismo o las cuestiones de género.

En su libro La paradoja de la globalización, Dani Rodrik analiza la cuestión de la globalización como un fenómeno que, lejos de concebirse como algo inevitable, es visto como una dimensión "política» que entra en colisión 
con otras dos variables igualmente "políticas», como son la soberanía nacional de los Estados y los principios democráticos que permiten expresar la voluntad ciudadana a través del voto popular. A su juicio, la relación entre estas tres dimensiones (globalización, soberanía estatal-nacional y democracia) es trilemática porque es materialmente imposible que todas ellas se vean satisfechas simultáneamente, de modo que «tenemos que elegir» dos variables en detrimento de una tercera. Aunque admite que la globalización siempre estará presente, de una manera u otra, en la vida política de los países, afirma que «voy a ser claro respecto a lo que elijo yo: la democracia y la autodeterminación nacional deben primar sobre la hiperglobalización» (Rodrik, 2012: 21). No podemos querer de forma maximalista las tres cosas a la vez porque van en direcciones opuestas y, por tanto, es necesario establecer un orden de preferencias entre ellas, excluyendo una de ellas como la opción menos deseable y aunando las dos restantes, a pesar de que no siempre las dos opciones elegidas armonicen entre sí de forma exitosa, porque, de hecho, la tercera opción nunca va a dejar de estar presente. En este sentido, el libro de Rodrik demuestra que cualquier orden de preferencias para resolver un trilema es un ejercicio complejo, paradójico y muy difícil de realizar en la práctica.

La tesis de la que parte este trabajo se basa en la pertinencia de recuperar este modelo triádico - y, por tanto, trilemático — para analizar la ideología moderna, a partir de los tres grandes pilares ideológicos - liberalismo, conservadurismo y socialismo- que se entrecruzan y se complementan entre sí. El esquema de este trabajo está organizado en cuatro partes. En la primera parte se analizan las reflexiones de dos autores de principios del siglo XX, John M. Keynes y Friedrich Hayek, que fueron pioneros en realizar una visión triangular de la ideología moderna, como la que aquí vamos a defender. Una triangulación, como veremos, que obliga a un ejercicio de gestión de situaciones incongruentes a través de las emociones. En la segunda parte observaremos que, tras la Segunda Guerra Mundial, este enfoque trilemático fue sustituido por el eje bipolar izquierda-derecha. Aunque se han dado algunas soluciones parciales para solventar los problemas inherentes a este esquema dual — por ejemplo, ampliar el análisis de la ideología a través de una lista muy amplia de ismos-, un esquema plural, aunque más operativo, basado en un modelo trilemático de ideología, podría ser una buena alternativa. Para observar las ventajas del modelo trilemático de ideología, en la tercera parte analizaremos cómo un concepto político concreto, la idea de igualdad, ha sido desarrollado en la teoría política sobre estos tres pilares ideológicos. Veremos que esta situación trilemática es, precisamente, la que hace muy difícil establecer distinciones ideológicas claras y explicaremos por qué las emociones asociadas a estos tres ejes ideológicos - mediante un mecanismo que llamaremos el trilema del trilero - ayudan a sortear las incongruencias lógicas que preside la relación 
entre ellas. Finalmente, en la cuarta parte de este trabajo, esbozaremos un modelo que permita analizar cómo utilizan los ciudadanos las distintas opciones ideológicas a la hora de valorar un determinado tema político, y, a partir de ahí, observaremos qué nuevos retos se abren para el estudio práctico de la ideología política.

\section{JOHN M. KEYNES Y FRIEDRICH HAYEK: LA EXTRAÑA PAREJA}

El enfrentamiento entre Keynes y Hayek en la primera mitad del siglo Xx ha sido una dialéctica intelectual ampliamente comentada (Wapshott, 2011). Muchos afirman que esta disputa representa un duelo entre dos visiones radicalmente distintas sobre la vida económica moderna: mientras Keynes aparece como el máximo artífice de la visión socialdemócrata de la economía, Hayek suele verse como el defensor neoliberal de la economía de mercado. Sin embargo, otros autores plantean que, en realidad, esta distinción es una construcción ideológica (Hoover, 1999) que amplifica unas diferencias sobre algo que, en realidad, nunca fue una disputa irreconciliable (Goodspeed, 2012). Especialmente, si se tiene en cuenta que, aunque coetáneos, escribieron en momentos distintos y eso permitió - especialmente a Hayek - modificar algunos de sus presupuestos económicos iniciales (Magliulo, 2013). Más allá de la discusión técnica entre economistas, y pese a su importancia, lo revelante que podemos resaltar aquí es que, en gran medida, ambos autores compartían una preocupación ideológica similar: saber cuál iba a ser el futuro del liberalismo moderno, un «liberalismo dividido» (Freeden, 1986), en plena transición histórica, dentro de un mundo caracterizado por la confrontación de sistemas de organización política (democracia, fascismo, comunismo) incompatibles entre sí, y todo ello en medio de un escenario internacional de alta volatilidad económica y social.

En 1925 John M. Keynes pronunció una conferencia que tituló de forma provocadora: «¿Soy un liberal?». La idea central de esta conferencia era manifestar sus dudas sobre las posibilidades futuras del liberalismo como ideología política ante las resistencias «intransigentes» del pensamiento conservador y el «catastrofismo» inherente, a su juicio, al pensamiento socialista radical (Keynes, 1925 [1988]: 302-303). En su opinión, la ideología liberal había cumplido una misión histórica durante los siglos de expansión capitalista, la llamada era de la abundancia — siglos XVII, XVIII y XIX — con la defensa del libre mercado, la libertad individual, la expansión económica y el mínimo control coercitivo del gobierno a las actividades individuales. Sin embargo, este ciclo histórico estaba a punto de terminar para dejar paso a otro dominado por las llamadas políticas regulatorias. (Rodrik señala que Keynes fue, posiblemente, el primer autor 
consciente de las tensiones que la globalización económica liberal produce sobre la ideología nacional-conservadora y sobre los valores progresistas.) Aunque estaba a favor de dichas políticas y se afanaba en mostrar sus bondades, Keynes era consciente de que la regulación era un argumento extraño al liberalismo y, de alguna manera, mucho más congruente con sus dos ideologías antagónicas: el conservadurismo y el socialismo. En el caso del conservadurismo, por su apelación nacionalista a proteger los intereses de los terratenientes locales, sus derechos de propiedad y el orgullo de la casta patriótica. En el caso del socialismo, porque la regulación permite luchar por unas condiciones materiales y un mundo nuevo frente a "la malignidad, la envidia y el odio" de aquellos que habían tenido históricamente la riqueza y el poder.

¿Qué podía hacer la ideología liberal moderna ante esta situación? Según Keynes, el liberalismo debía apostar por «controlar y dirigir las fuerzas económicas en interés de la justicia social y de la estabilidad social» (ibid.: 308) frente a los abusos que, en las esferas del gobierno económico, proponían tanto el fascismo como el bolchevismo. Es decir, el liberalismo debía ser capaz de volver a crear un espacio ideológico propio diferente del conservadurismo y el socialismo. Y esto mismo que era válido para el ámbito económico debía extenderlo a los otros cuatro grandes ámbitos - hoy diríamos, temas de campaña- en los que, a su juicio, se estaba planteando la lucha política moderna: el ámbito internacional, el ámbito de la política institucional, el ámbito de las cuestiones sexuales y el ámbito de los valores. En el campo de las relaciones internacionales, Keynes define el liberalismo como una ideología que fomente la paz y el desarme entre Estados, «aún a riesgo de parecer débiles» (ibid.: 304), frente al belicismo nacionalista y el internacionalismo beligerante del socialismo. En el ámbito de la política institucional, Keynes afirma que el liberalismo debía apostar por impulsar "corporaciones semiindependientes» (ibid.: 304) para gestionar la compleja actividad política, frente a las tareas de los ministerios y del Parlamento que, pese a su legitimidad democrática, en muchas ocasiones «serán inútiles» (ibid.: 304) para llevar a cabo la acción del gobierno. En el ámbito de lo que Keynes denomina cuestiones sexuales, el liberalismo debía apostar por «el control de la natalidad, el uso de anticonceptivos, la legislación matrimonial, el tratamiento de los delitos y anormalidades sexuales, la situación económica de las mujeres, la reforma del divorcio y la organización económica de la familia» (ibid:: 305), esto es, legitimar la autonomía de cada persona con independencia de su condición sexual. Finalmente, en el campo de los valores (que Keynes proyecta en temas específicos como las drogas, el alcohol y el juego, elevados a la categoría de «asuntos de Estado»), el liberalismo debía apostar por la tolerancia hacia «la evasión, las emociones, los estímulos» de "unas licencias razonables, unas saturnales autorizadas y un carnaval santificado» (ibid.: 305), frente al puritanismo 
conservador que aboga por la prohibición o el puritanismo progresista que aboga por la demonización del opio popular. En suma, para Keynes el liberalismo era una opción ideológica específica que, en relación con todos estos temas de la agenda política, tiene una posición diferente tanto de la ideología conservadora como del socialismo.

Es curioso que en 1959 Friedrich Hayek, tal vez imitando el estilo de Keynes, dictó una conferencia que tituló de forma igualmente provocadora: Por qué no soy conservador. Sorprende comparar ambas conferencias para observar las múltiples semejanzas en el tono y en la estructura, como si fueran las dos caras de una misma moneda. La idea más importante de este texto es su insistencia en analizar la ideología moderna como una "relación triangular» de tres vectores. Lo explica con meridiana claridad: «[...] se suele suponer que, sobre una hipotética línea, los socialistas ocupan la extrema izquierda y los conservadores la opuesta derecha, mientras los liberales quedan ubicados más o menos en el centro; pero tal representación encierra una grave equivocación. A este respecto, sería más exacto hablar de un triángulo, uno de cuyos vértices estaría ocupado por los conservadores, mientras socialistas y liberales, respectivamente, ocuparían los otros dos» (Hayek, 1959 [1982]: 516). Para Hayek, a quien en muchas ocasiones su liberalismo ha sido caricaturizado de manera simplista con calificativos como neoliberal o libertario, que él consideraba «demasiado artificioso y rebuscado» (ibid.: 527), este triángulo le permite señalar una importante diferencia entre su ideario liberal y la ideología conservadora a la que tanto se le suele asociar. Para Hayek, el conservadurismo es una ideología especialmente molesta por su oscurantismo, por su voluntad de aferrarse al pasado, por su aversión a lo nuevo, a lo foráneo, en definitiva, por su estrecha vinculación con uno de los grandes males que sacudió el mundo moderno en el tiempo en que Hayek escribió: el nacionalismo (ibid.: 524). En pocos textos se puede observar con mayor nitidez una diferencia ontológica entre el liberalismo filosófico de Hayek frente a la cercanía ideológica que, a su juicio, el conservadurismo guardaba con el nacionalismo.

Estos tres polos ideológicos —-socialismo, liberalismo y conservadurismo - tienden a diferenciarse, pero en muchas ocasiones - y esto es lo relevante- buscan su atracción, cuando no su solapamiento. Según Hayek, una de las similaridades morfológicas más raras de su tiempo - por usar la terminología de Michael Freeden (2003 [2013]: 83) — fue la aproximación conceptual y emocional de los postulados conservadores y socialistas frente al polo liberal; sucedía, por ejemplo, en su predilección por cierto autoritarismo gubernamental o su preferencia por ciertas políticas colectivistas y de carácter comunitarista frente a las fuerzas que regulan el mercado. Hayek temía — como buen liberal— que esa «amistad incongruente», basada en una 
especie de «odio compartido» entre socialistas y conservadores hacia lo liberal, fuera más habitual de lo esperado. Consideraba, con razón, que esta situación debilitaría enormemente la posición de la ideología liberal. Este argumento volvió décadas después en el debate entre liberalismo y comunitarismo, cuando se señalaron las sintonías entre los planteamientos ideológicos comunitaristas conservadores y los argumentos ideológicos comunitarios de izquierda por su común «aversión emocional» al individualismo liberal (Avineri y De-Shalit, 1992: 5; Mulhall y Swift, 1996: 70). Los análisis empíricos de Kitschelt y Hooghe que mencionábamos antes van ahora en esta misma dirección.

Hayek pensaba que los postulados socialistas y los postulados liberales tenían también elementos de aproximación frente a las tesis conservadoras como, por ejemplo, sus preferencias por los ideales del cambio y su orientación política hacia el futuro. Sin embargo, es difícil encontrar en Hayek una elaboración más amplia de esta idea. A diferencia del liberalismo de Keynes, que podía estar cerca de las posiciones ideológicas del socialismo aunque emocionalmente estaba lejos de su retórica clasista y obrerista, el liberalismo de Hayek se orientó siempre hacia la posición contraria. De hecho, como afirma con sus propias palabras, «hoy por hoy, en efecto, los defensores de la libertad no tienen prácticamente más alternativa, en el terreno político, que apoyar a los partidos conservadores» (Hayek, 1959 [1982]: 514). A su juicio, este salto entre ideologías partidistas es posible gracias a la ambigüedad que es inherente a sus postulados: se puede abrazar una ideología tanto por lo que dice como por aquello contra lo que emocionalmente se rechaza con más fuerza.

Es aquí, en este punto concreto, donde descubrimos ese fenómeno paradójico que aquí hemos denominado el trilema del trilero: un juego que consiste en mover una bolita escondida en medio de tres cubiletes para, en un momento dado, durante un ejercicio de persuasión, fusionar dos de estos cubiletes (el que tiene supuestamente la bolita y aquel otro donde supuestamente el ciudadano cree que está la bolita) con el objetivo de aislar el tercer cubilete restante. El objetivo de un trilero ideológico, por analogía con estos embaucadores de feria, es gestionar el movimiento de los distintos temas que conforman la acción política en medio de tres distintas ideologías. El momento clave del trilema del trilero en la conferencia de Hayek llega cuando afirma aquello de que «no parece encerrar grave peligro el denominar conservadores a los partidarios de la libertad, aun cuando, en más de una ocasión, a estos últimos ha de resultar embarazosa tan plena identificación con quienes sienten tan intensa aversión al cambio» (ibid.: 529). Para Hayek, un liberal puede sentir "aversión» al conservadurismo, pero puede superarla si su «aversión» hacia la tercera ideología es aún mayor. Es decir, el truco del trilero ideológico 
funciona cuando un nicho ideológico — en este caso concreto, el de los liberales - esconde la bolita en el nicho de uno de sus adversarios - en este caso, los conservadores- y consagra sus esfuerzos en mostrar que la bolita nunca puede estar en el nicho restante —en este caso, el de los socialistas-. De esta forma, según Hayek, se sortea la situación (emocionalmente) embarazosa de que un liberal, para ser liberal en la práctica, tenga que denominarse conservador. El mecanismo que permite sortear las incongruencias entre ideologías para que estos inconvenientes pasen a un segundo plano es la emoción compartida del "miedo a un tercero», sobre el cual es posible volcar toda la emocionalidad negativa. Difícilmente este salto se puede explicar con argumentos lógicos y racionales. Por el contrario, todo parece indicar que este ejercicio solo puede realizarse con argumentos emocionales. ¿Cómo resuelve Hayek el enigma? Según sus propias palabras, "dudo mucho que ningún auténtico investigador político pueda jamás ser de verdad conservador. La filosofía conservadora puede ser útil en la práctica, pero no nos brinda norma alguna que nos indique hacia dónde, a la larga, debemos orientar nuestras acciones» (ibid.: 301). Hayek afirma que el conservadurismo es sensiblemente tosco, pobre. En realidad, puede ser hasta chabacano. Además, es incongruente en términos formales y racionales con el liberalismo. Pero la empatía práctica entre ambos puede funcionar, especialmente cuando se activa la emocionalidad - llámese odio, temor o aversión, dependiendo de la intensidad y de las características específicas - hacia la "tercera ideología», en este caso, hacia la ideología socialista.

\section{DEL TRIÁNGULO ISÓSCELES A LA RECTA SOLO HAY UN PASO}

El modelo triangular defendido por Hayek entre conservadurismo, liberalismo y socialismo fue, de forma paulatina, convirtiéndose en un triángulo isósceles, en el que uno de los extremos (¿el liberalismo?) se fue apagando. Es posible que el liberalismo haya ido acomodando su estrategia hasta acabar subsumido en medio de los otros dos polos, que tienen más posibilidades de atraer la atención y de suscitar el entusiasmo de la opinión pública. De alguna manera, Hirschman ya planteaba esta misma tesis cuando insinuaba que la ideología liberal nunca tuvo el atractivo suficiente para eliminar lo que él llama «la tesis de los grilletes feudales» (1977 [2014]: 176-184): esto es, la fuerza necesaria para domesticar el imponente atractivo que el conservadurismo ha tenido siempre para frenar toda posibilidad de avance liberal ilimitado, sea en lo económico o en lo social. Si a esto sumamos la explicación de Thomas Piketty, según la cual los rentistas improductivos son hoy los grandes adalides del conservadurismo político moderno 
(Piketty, 2013 [2014]: 643) frente a las fuerzas representadas no solo por los emprendedores económicos liberales sino por el propio Estado social y las fuerzas laborales activas, es fácil entender las limitaciones que la ideología liberal ha ido encontrando a su paso para tener voz propia. En este sentido, la estrategia de Hayek de atraer el liberalismo hacia los valores de uno de esos polos - en su caso, el conservadurismo- es más fácilmente entendible. Aunque este movimiento ha implicado un riesgo analítico serio: confundir los valores y los principios liberales con los valores propios del conservadurismo político.

Tras la Segunda Guerra Mundial, como ya el propio Hayek sospechaba, la reflexión teórica sobre la cuestión de la ideología provocó un cambio de paradigma, con el objetivo de simplificar su estudio en torno a dos polos extremos y una posible variabilidad gradual entre ambos (Knight, 2006). Los dos principales paradigmas analíticos de la ciencia política, tanto la teoría de elección racional como el behaviorismo, se pusieron a trabajar para dar a la ideología un carácter más lógico, más binario y, sobre todo, más desapasionado. En el caso de la teoría racional, la aportación de Downs fue señalar que, contrariamente a lo que se suponía, las ideologías políticas no son emocionales sino racionales porque "la falta de información crea una demanda de ideologías en el electorado y cada partido inventa una ideología para atraer los votos de aquellos ciudadanos que desean reducir sus costes votando ideológicamente» (Downs, 1957 [1992]: 101). Downs criticaba el multipartidismo y la dispersión ideológica porque impedía formar gobiernos definidos, coherentes e integrados. Por esta razón, creía que los sistemas políticos tenderían al bipartidismo - cabría añadir, a la reducción ideológica a dos opciones lo más centrípetas posibles-. Como señala Peter Mair, el aumento del número de partidos, y especialmente de partidos centrífugos de ideología populista en los últimos treinta años, sobre todo en Europa Occidental, desmiente en gran medida esta tesis (Mair, 2013 [2015]: 120-121).

En el caso del behaviorismo, el trabajo de Lipset y Rokkan en 1967 sobre partidos políticos y dimensiones ideológicas es un ejemplo sobre cómo se empezó a trabajar el análisis de la ideología de forma empírica. En dicho estudio, planteaban que la ideología política moderna estaba atravesada por cuatro grandes cleavages duales que dividían a la sociedad moderna: urbano $v s$. rural; secular $v s$. religioso; capital $v s$. trabajo; centro $v s$. periferia. La tesis general de este trabajo, y de otros que han venido después, es que las tres primeras dimensiones eran perfectamente integrables en una escala ideológica izquierda-derecha (Lipset y Rokkan, 1967), mientras que la última dimensión, centrada en la cuestión centro $v s$. periferia, tenía una relación más especial (Rokkan, 1980). A día de hoy, la discusión sigue abierta entre 
incluir esta última cuestión como una posición intermedia en el contínuum de la escala ideológica izquierda-derecha (Knutsen, 1997, 1998) o, por el contrario, considerar la dimensión centrada en la cuestión nacional como una ideología fuera de este espacio bipolar.

En España, la mayor parte de la literatura académica empírica que ha tratado la cuestión ideológica izquierda-derecha y la cuestión nacional centro-periferia opta en sus estudios por utilizar dos escalas diferentes (Pallarés, 1991; Padró-Solanet y Colomer, 1992; Lago, 2000; Fernández-Albertos, 2002; Torcal y Medina, 2002, 2007; De la Calle, 2005; Balcells, 2007; Llera, 2010; De la Calle, Martínez y Orriols, 2010; Medina, 2015), dando por supuesto que ambas escalas forman una especie de matriz de los cuatro posibles posiciones ideológicas diferentes. En general, esta manera de analizar/medir la ideología suele considerarse estable y fiable porque es fácil de preguntar y su utilización ofrece una alta variabilidad de respuestas, aunque, como advierten algunos trabajos, estas variables ideológicas también tienen un nivel razonable de no respuesta: en España, por ejemplo, el índice de personas «sin autoubicación ideológica» en la escala izquierda-derecha está en torno al 14\% de los encuestados (De la Calle, Martínez y Orriols, 2010: 112). Sin embargo, más allá de esta cuestión, cabe preguntarse hasta qué punto la autoubicación de los ciudadanos en estas dos escalas es una forma solapada de reflejar las múltiples dimensiones con las que los ciudadanos construyen su ideología. Habitualmente, la escala izquierda-derecha suele usarse como una variable independiente de la escala nacionalista porque se da implícitamente por supuesto que todos los ciudadanos entienden lo mismo (autoubicarse en la «ideología de derecha» en Murcia sería igual que hacerlo en el País Vasco) y construyen su respuesta sobre un abanico similar de dimensiones que tienen un peso semejante. Sin embargo, no está tan claro que esto sea así. Más bien al contrario, ocurre que la dimensión nacional influye de forma diferente en los distintos territorios a la hora de su autoubicación ideológica en la escala izquierda-derecha y tal vez sería más sensato analizar previamente qué factores están incidiendo a la hora de analizar las respuestas de los ciudadanos dentro de esta misma escala (Leonisio y Strijbis, 2014). Finalmente, relacionando todo lo que aquí se plantea, cabe preguntarse si realmente cualquier ideología (sea izquierda-derecha o nacionalismo) funciona en la práctica a través de dos escalas o, por el contrario, todas estas opciones ideológicas escapan a una relación lineal.

Desde 2006 el Centro de Investigaciones Sociológicas (CIS) ha introducido en sus barómetros una solución parcial a los problemas de las escalas ideológicas: preguntar una variable nominal que analice la ideología a través de múltiples categorías de respuesta. La tabla 1 presenta los resultados hasta 2015. 
Tabla 1. Autodefinición ideológica de los encuestados en España y el Pais Vasco, 2006-2015

\begin{tabular}{|c|c|c|c|c|c|c|}
\hline & \multicolumn{2}{|c|}{ España $\left(1 .^{a}\right.$ opt $)$} & \multicolumn{2}{|c|}{ España $\left(2 .^{a}\right.$ opt $)$} & \multicolumn{2}{|c|}{ País Vasco } \\
\hline & Md & Dt & Md & Dt & Md & Dt \\
\hline & $2006-15$ & 2006-15 & $2010-15$ & $2010-15$ & 2009-12 & $2009-12$ \\
\hline Conservador/a & 11,9 & 1,0 & 2,3 & 0,4 & 4,0 & 1,8 \\
\hline $\begin{array}{l}\text { Demócrata } \\
\text { Cristiano/a }\end{array}$ & 5,2 & 1,0 & 2,8 & 0,4 & 2,9 & 0,3 \\
\hline Liberal & 12,8 & 1,2 & 4,9 & 0,6 & 7,4 & 1,7 \\
\hline Progresita & 8,8 & 0,7 & 5,8 & 0,7 & 6,1 & 0,0 \\
\hline Socioaldemócrata & 6,5 & 1,3 & 3,3 & 0,6 & 5,5 & 0,8 \\
\hline Socialista & 15,7 & 2,8 & 3,4 & 0,5 & 12,2 & 1,3 \\
\hline Comunista & 2,0 & 0,4 & 0,9 & 0,2 & 2,2 & 0,1 \\
\hline Nacionalista & 3,6 & 0,5 & 1,7 & 0,3 & 25,1 & 1,4 \\
\hline Feminista & 1,2 & 0,3 & 2,3 & 0,4 & 1,7 & 0,2 \\
\hline Ecologista & 4,5 & 0,5 & 6,1 & 0,8 & 4,4 & 0,2 \\
\hline Otro & 3,8 & 1,2 & 1,6 & 0,4 & 2,7 & 0,6 \\
\hline Apolítico & 5,5 & 1,7 & 0,2 & 0,1 & 1,4 & 1,1 \\
\hline NS & 15,1 & 1,1 & 27,5 & 10,4 & 20,3 & 3,7 \\
\hline $\mathrm{NC}$ & 6,2 & 1,7 & 38,0 & 10,4 & 8,3 & 2,1 \\
\hline
\end{tabular}

Fuente: CIS. La categoría feminista se introdujo en enero de 2010 (estudio 2828) y la categoría progresista en enero de 2011 (estudio 2859). La segunda opción se introdujo en abril de 2010 (estudio 2834).

Sin duda, esta pregunta tiene el mérito de intentar ir más allá de la polaridad ideológica de la escala izquierda-derecha. Sin embargo, sus resultados son escasos, tal vez debido al propio diseño de la variable. En primer lugar, esta pregunta pretende ser más amplia que la anterior para reducir el número de no respuesta, pero en realidad no lo consigue (en el caso de la primera opción, el NS/ NC supera el $20 \%$ pero es que en el caso de la segunda opción la no respuesta supera el $60 \%$ ). Da la sensación de que el listado de categorías es demasiado amplio y no está claro que las diferencias entre las categorías sean, en todos los cosas, similares. (Freeden diría con razón que, en realidad, no hay tantas ideologías en el espectro político.) En segundo lugar, esta pregunta intenta superar el 
carácter lineal de la escala, pero, en realidad, acaba siendo una variable lineal quebrada, es decir, sesgada: tal como está preguntada, intenta respetar una linealidad clásica desde la categoría conservadorla hasta la categoría comunista, en la que progresista (¿?) sería la categoría intermedia, a la que luego se añaden, a modo de categorías nuevas (nacionalista, feminista y ecologista), una serie de etiquetas que, en teoría, se consideran con entidad suficiente para salir del anonimato que impone la categoría de otro. Finalmente, esta pregunta sigue sin solucionar de forma adecuada el carácter multidimensional y la intensidad — moderada vs. extrema - de la ideología de los encuestados, un tema cada vez más importante según hemos visto antes (Kitschelt, 1994; Hooghe et al., 2002; Ignazi, 2003). Si, como sugieren estos autores, la identificación y la intensidad ideológica cambia en función de cada tema, esta variable nominal no resuelve el problema sino que, más bien, lo amplifica.

\section{LA IDEOLOGÍA ES COSA DE TRES}

Freeden critica que el eje dicotómico izquierda-derecha «sirve al propósito de conferir un aura de moderación a las ideologías", pero este planteamiento «es esencialmente ideológico» (Freeden, 2003 [2013]: 106). Es posible realizar otro tipo de aproximación analítica de la ideología basándose en la existencia de una pluralidad de ismos, pero sin caer tampoco en la enumeración de etiquetas elegidas por simple acumulación nominal, como hemos visto líneas más arriba. La cuestión es saber cómo es la relación entre ideologías cuando el número es superior a dos.

Tomemos un ejemplo: la dinámica ideológica de Reino Unido en las últimas décadas. Durante años este país ha sido considerado un ejemplo de bipartidismo ideológicamente centrípetro, reforzado por un sistema electoral muy desproporcional que desincentiva las tendencias ideológicas centrífugas y el multipartidismo. Un país, por tanto, idóneo para que la dinámica izquierdaderecha funcione con cierta facilidad. Sin embargo, lo que se observa en este país en los últimos cuatro años es, por un lado, un aumento del multipartidismo - con grandes partidos a nivel estatal y un gran partido nacionalista regional en Escocia - y, por otro lado, un reforzamiento de tres claras líneas ideológicas: una izquierda más o menos socialista, una corriente liberal y una corriente nacionalista (no solo escocesa... sino también nacionalista inglesa). Esta última, aunque no mencionada en muchos trabajos que estudian las dinámicas ideológicas de este país, lleva desarrollándose con fuerza al menos desde la época de Margaret Thatcher (Alonso y Claro de Fonseca, 2012: 881). Es significativo que el Partido Conservador, ante la debilidad política del Partido Liberal, ha sido visto en muchas ocasiones como un partido fundamentalmente liberal, pero 
pocas veces se ha analizado su carácter conservador y/o nacionalista, dando a entender que liberalismo y conservadurismo eran ideologías intercambiables, cuando de hecho no lo son (Riker, 1982; Fairclough, 1989). Esta ocultación analítica - podríamos decir, un juego de trilero- ha sido significativa si tenemos en cuenta que esto ha impedido conocer la importancia que el nacionalismo espoleado por la guerra de las Malvinas jugó en la reelección de Thatcher en 1983 o el peso que la oposición nacionalista al proceso de construcción europea tuvo en su reelección de 1987 (Tilley y Heath, 2007; Dyson, 2009; Evans, 2013). Si pensamos en el papel que el nacionalismo inglés ha jugado en las últimas elecciones del 7 de mayo de 2015 a nivel interior — ante el llamado peligro escocés - y a nivel exterior — con la dinámica antieuropea presente en el marco político británico, agravada tras la irrupción de fuerzas políticas como UKIP y el reciente referéndum del 23 de junio de 2016 para la salida del Reino Unido de la Unión Europea-, es fácil imaginar las limitaciones de la variable izquierdaderecha para interpretar la escena ideológica británica (Cutts y Goodwin, 2014). Especialmente si la etiqueta «derecha» solapa dos ideologías (liberalismo vs. conservadurismo/nacionalismo) que son contrarias entre sí y dicha etiqueta impide saber el peso real de cada ideología.

Para superar estos problemas, una posible alternativa para analizar la ideología debería tener en cuenta los siguientes seis elementos: a) el número de opciones ideológicas analizables debería ser lo suficientemente complejo para evitar una bipolaridad dudosa que oculta la relación triangular que existe entre las opciones ideológicas; por ello creemos que el número óptimo de la pluralidad serían tres opciones ideológicas: liberal, socialista y conservador/ nacionalista; b) dichas opciones deberían ser preguntadas con la suficiente claridad, no mediante etiquetas directas sino a través de preguntas indirectas que reflejen las tres posiciones ideológicas, para reducir así el nivel de no respuesta de los ciudadanos; c) debería tenerse en cuenta que los distintos temas de la agenda política de un país - economía, política interior, política internacional, cuestiones de género y cuestiones éticas - no se construyen ideológicamente de la misma manera, puesto que los ciudadanos pueden atribuir a cada tema una posición ideológica distinta; d) las tres opciones ideológicas deberían permitir que fueran ordenadas en función de su mayor o menor preferencia: si una persona tiene que opinar sobre un tema sabiendo que tiene tres opciones ideológicas distintas, podría elegir una opción pero también podría elegir una segunda opción frente a una tercera; e) las tres opciones podrían ser ponderadas en función de su mayor grado de simpatía o antipatía: es posible que la distancia afectiva hacia las tres opciones sean distinta, no siempre equidistante, en función de la moderación o la radicalidad ideológica; finalmente, f) se debería tener en cuenta que los distintos temas de la agenda no tienen el mismo peso en la política de un país ni en las preferencias de los electores. 
La hipótesis que aquí sostenemos es que ese juego trilemático entre ideologías implica que la relación de los ciudadanos con cada ideología es ambivalente (Laponce, 1978) y que, por tanto, las emociones políticas (simpatía, aversión, miedo) son las que ayudan a gestionar esta indeterminacion. Generalmente, los argumentos lógicos que una persona utilizaría para elegir una ideología como su primera opción frente a las otras dos no son los mismos argumentos lógicos que utilizaría luego para rechazar la última opción frente a la segunda, o simplemente para ordenar todas ellas. Si una persona defiende una ideología A y utiliza un argumento lógico-racional para criticar la posición de la ideología $\mathrm{B}$ pero no le sirve para criticar la posición de la ideología $\mathrm{C}$, el argumento será nulo... salvo que dicho argumento se convierta en un recurso emocional. Por ejemplo, tal como Hooghe et al. han comprobado en su estudio sobre el proceso de integración europea, los argumentos lógicoracionales de un votante conservador de extrema derecha contrarios al modelo europeo actualmente vigente le permiten estar en contra de los argumentos de un votante moderado pero, sin embargo, este mismo argumento no le sirve para criticar la ideología de un votante de extrema izquierda... salvo que, en términos emocionales, estos votantes conservadores extremistas desvíen sus argumentos racionales hacia recursos emocionales (la «simpatía del extremismo») que les permitan fortalecer su aversión emocional compartida hacia el liberalismo moderado (Hooghe et al., 2002). A medida que las posiciones ideológicas se vuelven emocionales, estas son capaces de fortalecer su núcleo central y volverse inmunes a las argumentaciones cruzadas que pueden ser incompatibles entre sí. Como hemos visto en el juego trilemático a que se vio abocado Hayek (optar por el conservadurismo en lugar del liberalismo con el objetivo de hacer frente emocionalmente al socialismo), la ordenación de las preferencias ideológicas en situaciones trilemáticas obliga al uso de una racionalidad política que no siempre es lógica ni argumentativamente racional sino más bien se apoya en cuestiones emocionales (De Sousa, 1990).

En las próximas líneas vamos a intentar analizar cómo este mismo juego trilemático que invita al uso de una argumentación emocional más que a una racionalidad lógica se está produciendo también con bastante asiduidad en la teoría política a propósito del análisis de los conceptos. Un concepto donde se observa esto con bastante claridad es en la idea de igualdad.

\section{LAS TRES CARAS IDEOLÓGICAS DE LA IGUALDAD}

El concepto de igualdad es uno de los temas más relevantes de la vida pública en las últimas décadas, sobre todo ante la preocupación por las crecientes situaciones de desigualdad material que están produciéndose en las 
sociedades modernas (Gilens, 2012; Duflo, 2012; Therborn, 2013; Gornick y Jäntti, 2013; Sernau, 2014; Atkinson, 2015). Las respuestas de la teoría política ante esta cuestión son, desde hace tiempo, abundantes (Máiz, 2015). Es cierto que muchas de estas discusiones teóricas son controversias técnico-conceptuales, con un grado elevado de sofisticación, sobre distintas cuestiones, como el problema normativo de la métrica y la medición de la igualdad (Nagel, 1991; Sen, 1992, 2006; Parfit, 1997; Kaufman, 2015; Hirose, 2015) o el llamado problema del igualitarismo de la suerte, que incide sobre una cuestión más general, como es la justicia distributiva (Dworkin, 2000; Knight, 2009; Lazenby, 2010; Anderson, 2015; Miller, 2015). Sin embargo, hay que recordar que, en todos estos debates teóricos y prácticos sobre la igualdad, la ideología política juega un papel muy relevante (Cohen, 1989: 933). No se plantea del mismo modo el análisis teórico de la igualdad si los autores consideran previamente que la igualdad consiste en: a) conocer las condiciones formales para lograr una mayor equidad, o b) conocer a qué sujetos hay que reconocer la igualdad, o, por el contrario, se trata de c) observar la desigualdad como una dimensión sistémica del orden social. Como afirma Freeden, lo importante en una ideología no son los conceptos empleados sino la «organización estructural que atribuye significados despolemizados a una serie de conceptos políticos que se definen entre sí mutuamente» (Freeden, 2003 [2013]: 79).

Siguiendo con el esquema triangular que hemos propuesto en este texto, vamos a agrupar las distintas reflexiones teóricas sobre la idea de igualdad en torno a tres polos ideológicos. Por un lado, el polo de la igualdad liberal, representado por el concepto de «justicia como equidad» en la obra de John Rawls. Por otro lado, el polo de la igualdad comunitaria — que podemos calificar de conservadora y/o nacionalista en el lenguaje de las ideologías políticas-, representado por el concepto de «igualdad patriótica» en la obra de Alasdair MacIntyre. Finalmente, el polo de la igualdad socialista, representada en la obra de Gerald A. Cohen, especialmente en el concepto de «igualdad sistémica» presente en sus últimos trabajos.

a. El concepto de igualdad liberal está vinculado, a partir de la obra de John Rawls, con la idea de que la equidad es la consecuencia de unas condiciones formales e institucionales justas que una sociedad tiene con el propósito de que sus ciudadanos tengan la misma consideración y el mismo respeto recíproco, con independencia de sus diferencias económicas, sociales, culturales, sexuales, religiosas, etcétera. Como señala Máiz (2015), el concepto de igualdad liberal inspirado en la idea rawlsiana de justicia como equidad es una idea teóricamente muy fértil, pero a lo largo del tiempo ha sufrido numerosas reformulaciones, especialmente en los debates sobre la concepción de la igualdad como algo limitado o no a lo público (Dworkin, 1985); la medición de la desigualdad (Hirose, 2015); el papel de las instituciones políticas a la hora de 
ejercer políticas redistributivas (Van Parijs, 1991); las virtudes o no de las prácticas de discriminación positiva para lograr criterios igualitarios finalistas (Roemer, 1996); o la importancia de las ideas de mérito y responsabilidad individual en la consecución funcional de la idea de igualdad (Knight y Stemplowska, 2014).

Como es sabido, toda la teoría de Rawls, acusada de forma inapropiada de ser una simple continuación sofisticada del modelo contractualista de tradición lockeana o una subvariante extraña de las teorías de elección racional, se basa en un original mecanismo, el llamado velo de la ignorancia, que es el que permite a los individuos llegar a los principios de justicia, entre ellos a la idea de la equidad. Según Rawls, la originalidad de este planteamiento está en que la igualdad como principio de justicia no se obtiene como consecuencia de un procedimiento de deliberación racional que finaliza en un contrato formal entre los individuos porque, de alguna manera, su capacidad racional para firmar dicho contrato - se entiende: una racionalidad instrumental orientada a la defensa de los intereres individuales de los participantes - está, de alguna manera, velada, a mitad de camino entre la total transparencia y la total opacidad. Los individuos, dirá Rawls, no son racionales, son algo mejor: son razonables porque construyen sus condiciones equitativas de la vida pública «en términos de reciprocidad y mutualidad, a diferencia de lo racional, que expresa la concepción de simple ventaja personal de cada participante» (Rawls, 1980 [1986]: 152). Robert Nozick, en su famosa crítica, dirá que la posición de Rawls es incongruente y no puede sostenerse de forma lógica porque pretende defender los procedimientos liberales para llegar a situaciones de equidad a través de ciudadanos que no saben, por su propia ignorancia escondida detrás de un velo, cuáles son las condiciones justas de equidad que exactamente estarían negociando (Nozick, 1974 [1990]: 208). Como explica Máiz, la clave para entender la igualdad liberal de Rawls es comprender que tras el velo de la ignorancia y su idea de razonabilidad hay implícitamente ciudadanos que están predispuestos a la sociabilidad, esto es, sujetos con «sensibilidad moral» (Máiz, 2010: 40-41). Sin este componente emocional, la teoría rawlsiana estaría expuesta a la incomprensión, a la tergiversación o al descrédito.

b. El concepto de igualdad comunitaria ha tenido un recorrido teórico igualmente relevante, tal vez sin la centralidad que ha ocupado la propuesta liberal de John Rawls, pero con la suficiente fuerza para conectar la idea de igualdad con la existencia de comunidades políticas que desean conservar sus tradiciones y valores específicos. Este concepto de igualdad comunitaria, como decíamos, puede ser defendido por familias ideológicas que habitualmente se analizan por separado, como son el conservadurismo y el 
nacionalismo, pero que, sin embargo, como explica Freeden (1998), tienen bastante en común en la medida que el conservadurismo «se siente cómodo ofreciendo un espacio de relación en su seno al nacionalismo que se nutre de una historia inventada y de un territorio exclusivo" (Freeden, 2003 [2013]: 126). Quizá el ejemplo más claro de esta idea teórica de igualdad conservadora, que une conservadurismo y nacionalismo en torno al concepto de patriotismo sustantivo, sea el concepto de «igualdad patriótica» que propone Alasdair MacIntyre.

Para MacIntyre, la igualdad es sustantivamente social y particularmente situada, por lo tanto, ni es abstracta ni universalizante, como plantea la igualdad simple de inspiración liberal. Es el resultado, no de un estado «emotivista» individualista (MacIntyre, 1981 [1988]: 22) incapaz de identificarse con ningún valor moral, sino el producto de nociones de bienes insertas en la tradición, en los valores patrióticos de una comunidad y en los bienes sociales que dicha comunidad desea preservar. Según este autor, el patriotismo ha de ser considerado una virtud aunque contradiga los principios universales de imparcialidad moral, porque el patriotismo es «la lealtad a una nación en particular que sólo aquéllos que poseen esa particular nacionalidad pueden exhibir» (MacIntyre, 1984: 4). La ubicación social de los individuos dentro de comunidades locales es posible porque en esos ámbitos existe una cultura tradicional y una lengua común que comparten por igual todos sus habitantes, la cual permite la comunicación entre ellos a todos los niveles, tanto a nivel formal como simbólico (MacIntyre, 1988 [1994]: 353). Cada uno de nosotros, recalca MacIntyre, «hasta cierto punto entiende su vida como una narración representada; y por nuestra relación con otros tenemos que entendernos como personajes de narrativas representadas de las vidas de otras personas» (MacIntyre, 1984: 16). Para comprender la igualdad de nuestras vidas y por tanto ser capaces de vivir una vida moral significativa, necesitamos la experiencia emocional de una comunidad nacional. Lo que el patriotismo como sentimiento moral ofrece frente a la crítica racional es que «la nación es concebida como un proyecto, un proyecto nacido de alguna forma en el pasado y continuado para que [aparezca] una comunidad distintivamente moral» (MacIntyre, 1984: 13-14).

Las críticas a este modelo han sido muchas, especialmente desde enfoques liberales y progresistas. Gutman, por ejemplo, señala que esta visión de la igualdad construida sin tener en cuenta la voluntad individual de los ciudadanos no permite distinguir a una democracia liberal de prácticas dictatoriales o de tipo sectario (Gutman, 1985 [1992]: 131). Asimismo, esta idea de la igualdad comunitaria corre el riesgo de dejar a los ciudadanos atrapados en una comunidad que podría justificar prácticas de carácter racista e incluso 
militarista (Greiff, 1989: 99-116). La respuesta que ofrece MacIntyre es curiosa: a su juicio, en el tema del patriotismo hay que diferenciar las virtudes de la comunidad hacia dentro y las virtudes de la comunidad hacia fuera (MacIntyre, 1991 [1992]: 110): a su juicio el patriotismo está justificado con carácter defensivo, no ofensivo, en la medida que sirve para garantizar la supervivencia de una comunidad. Para que la igualdad comunitaria funcione, los ciudadanos deben respetar como límite la idea de la propia preservación de la comunidad. ¿Cómo se da contenido a este límite? Mediante la apelación a los sentimientos de la comunidad de referencia. A su juicio, la igualdad comunitaria puede ser compatible con ciudadanos críticos que pueden introducir cambios en dicha comunidad, pero para ello tendrán que demostrar a la comunidad que sus motivaciones, en realidad, no son egoístas sino altruistas, es decir, están basadas en sentimientos patrióticos y heroicos (MacIntyre, 1981 [1988]: 48) orientados emocionalmente a la actualización de la vida de esa comunidad. En definitiva, para ser un buen patriota dentro de una comunidad, todos los ciudadanos podemos ser iguales.

c. El concepto de igualdad socialista ha tenido, igualmente, cierto recorrido histórico, especialmente entre la tradición de izquierdas. Como afirma Máiz, este concepto ha sufrido en los últimos tiempos un problema de visibilización y de articulación conceptual en la medida que incorporó dimensiones que le eran ajenas, especialmente aquellas centradas en el análisis de las desigualdades individuales y cierta racionalidad instrumental del sistema en lugar de analizar la desigualdad de manera más estructural y sistemática, apelando por tanto a una emocionalidad mucho más comunitaria (Máiz, 2015). La obra de uno de los más prominentes defensores de esta idea de igualdad socialista, Gerald A. Cohen, es un ejemplo relevador: si en sus primeras obras su trabajo se centró en las condiciones más concretas sobre los problemas de la igualdad en el acceso a las condiciones de bienestar $(1989,1990,2000)$ y posteriormente se enfrascó en la discusión más técnica y posibilista sobre el llamado «igualitarismo de la suerte» (2008), en la parte final de su obra se aprecia un énfasis hacia posiciones más claramente sistémicas en las que interpreta el análisis de la igualdad más allá del enfoque individualista para plantear como opción la idea de que la igualdad debe ser entendida como un fenómeno holístico (2009, 2011, 2012, 2013). Para ello, según Cohen, es necesario que los ciudadanos sientan que forman parte de una comunidad, en la que sus motivaciones estarían orientadas por un cierto ethos igualitario (Casal, 2013; Carens, 2015) de carácter fraternal.

La cuestión de la igualdad socialista nos remite, en última instancia, a la cuestión sobre las condiciones sustantivas, materiales y no procedimentales, a partir de las cuales es posible pensar la igualdad. Para ello, como señala este enfoque, sería conveniente eludir cualquier consideración centrada en el ethos 
individualista, que considera las políticas de justicia distributiva como una «discutible limitación de la autonomía» o cree que la igualdad es un atributo que debiera medirse a través de la agregación más o menos equivalente de intereses y recursos repartidos entre las personas. Este enfoque de la igualdad, concebido como paliativo, no afrontaría el análisis sobre el origen de la desigualdad y, por tanto, difícilmente podrá contener su progresión histórica. Por el contrario, el enfoque sistémico de la igualdad socialista plantea la conveniencia de crear una estructura, no solamente formal sino material, con amplia presencia activa de los poderes públicos y las instituciones del Estado, que podría revertir la lógica individualista de relación propia de un igualitarismo redistributivo por una lógica más social y más comunitaria propia de un igualitarismo cooperativo. Al final, todo esto solamente sería posible si los ciudadanos sienten que esa emoción de fraternidad justificaría y daría soporte a semejante constructo. Sin el componente emocional de la fraternidad, este modelo sería imposible.

\section{IGUALDAD, IDEOLOGÍAS Y EMOCIONES. UNA PROPUESTA DE ANÁLISIS}

Las tres caras ideológicas de la igualdad — liberal, conservadora/nacionalista y socialista - forman un triángulo de relaciones semánticas inestables: algunas veces generan situaciones de colisión (todas contra todas) y otras veces generan situaciones de colusión (acercamiento de dos frente a una tercera). Esta perspectiva relacional de las ideologías es interesante porque obliga a observar conceptos políticos como la igualdad, no tanto en función de su presencia o ausencia dentro de una ideología concreta — en realidad, todas las ideologías hablan en algún momento de la igualdad-, sino más bien en función de la posición real que dicho concepto ocupa en la relación triádica entre las tres ideologías. Habitualmente, en los esquemas binarios, se suponía que, ante dos alternativas, se elige una y se rechaza la otra de forma automática porque las opciones son fácilmente incompatibles. Esta es la visión que se tiene de las ideologías cuando se las considera un atajo cognitivo que los ciudadanos utilizan para hacer frente a la incertidumbre política: algo así como "¿en qué piensa Ud. de forma instintiva cuando le viene a la cabeza la idea de igualdad en un determinado tema político X?». Sin embargo, en un esquema múltiple donde hay al menos tres opciones, cuando se elige una opción ideológica sobre un tema ello implica rechazar varias, y la cuestión es que ese rechazo no siempre tiene que estar motivado por la misma razón, sino por varias. Y estas razones, además, no siempre tienen que ser congruentes entre sí. Para entender cómo es posible que la posición numéricamente minoritaria de una 
ideología se fortalezca frente a las otras dos ideologías rivales, una buena solución práctica suele ser la invocación a la existencia de un fuerte sentimiento moral.

Desde la teoría política y la historia de los conceptos, el análisis de las emociones está ofreciendo interesantes aportaciones al conocimiento de las ideologías (Plamper, 2014). Uno de los autores más relevantes, William Reddy, considera que una manera apropiada para entender los distintos polos ideológicos sería concebirlos como "regímenes emocionales» (2001: 114118), esto es, conjuntos de emociones normativas, expresiones verbales (emotives) y rituales que permiten a los ciudadanos ordenar los sentimientos que proyectan sobre sus decisiones y, de esta manera, priorizar mejor las posibles alternativas. En la medida en que estos regímenes emocionales son «refugios» protectores pero no son compartimentos cerrados, Reddy habla del principio de «singladura emocional», esto es, apela a los regímenes emocionales como estructuras abiertas donde la libertad sentimental de los ciudadanos es la que crea la relación, la tensión y la posible combinación entre los distintos regímenes. Como afirma Sharon Krause en Civic Passions, en la deliberación democrática entre opciones ideológicas es tan importante las motivaciones positivas que ayudan a formar un juicio político como la aversión negativa hacia aquello que una ideología determinada puede considerar maligno o despreciable (Krause, 2008: 99-100).

En el caso que aquí hemos presentado, las tres ideologías hablan de la igualdad a través de distintos sentimientos, tal como están representados en el gráfico 1. Es decir, la concebida como un sentimiento razonable (R), como un sentimiento patriótico $(\mathrm{P})$ o como un sentimiento fraternal (F). El sentimiento de la igualdad razonable $(\mathrm{R})$ es aquella posición ideológica que ve la igualdad como una especie de "espacio de oportunidad" para todos los individuos sin que esto tenga que estar conectado con sentimientos ni patrióticos ni fraternales; el sentimiento de la igualdad patriótica $(\mathrm{P})$ es aquella posición ideológica que ve la igualdad "principalmente entre los míos» sin que esto tenga que estar conectado con sentimientos ni razonables ni fraternales; finalmente, el sentimiento de la igualdad fraternal $(\mathrm{F})$ es aquella posición ideológica que ve la igualdad como un «atributo de humanidad» que es inherente a nuestra condición de miembros de la misma especie sin que esto tenga que estar conectado con sentimientos ni razonables ni patrióticos. 
Gráfico 1. Las tres caras de la igualdad (y sus combinaciones complementarias)

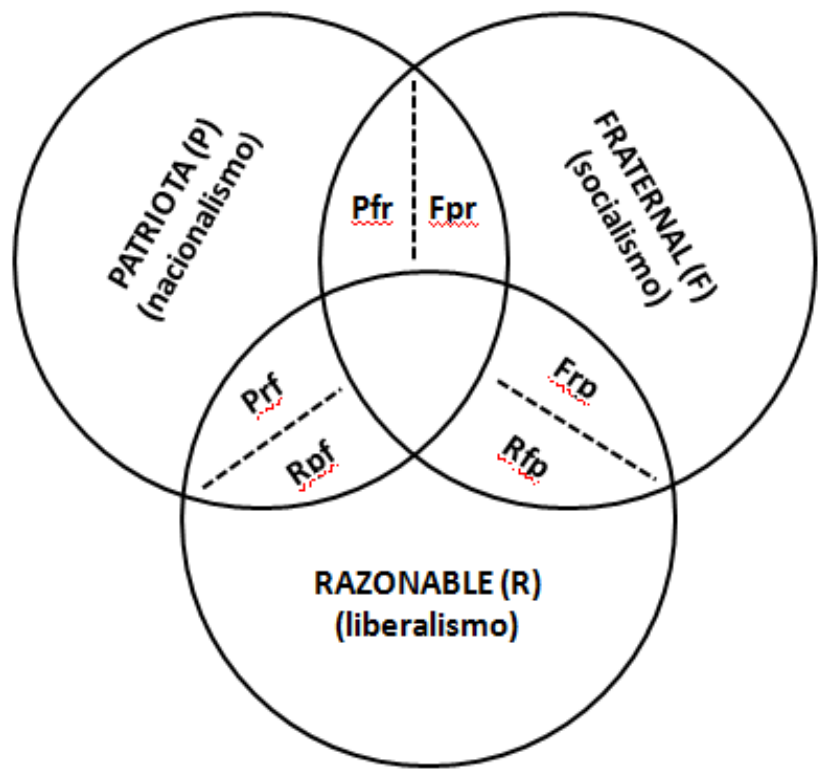

Fuente: elaboración propia.

Imaginemos que, en un cuestionario o en cualquier formato diseñado para obtener información analítica, los ciudadanos tuvieran que ordenar y ponderar tres afirmaciones relacionadas con el concepto de igualdad asociadas con un determinado asunto político (por ejemplo, tres determinadas soluciones propuestas sobre la situación económica de los inmigrantes en el país): una primera afirmación que hiciera referencia al carácter razonable de un sistema económico donde prime la eficiencia en la asignación escasa de recursos, la igualdad de oportunidades y la obtención de resultados en función del mérito y del esfuerzo individuales; una segunda afirmación que hiciera referencia al carácter patriótico de un sistema económico que primara la igualdad de los ciudadanos de la misma comunidad nacional a la hora de gestionar, proteger y disfrutar de los recursos económicos de un territorio; y una tercera afirmación que hiciera referencia al carácter fraternal de un sistema económico que primase el carácter sustantivo de igualdad redistributiva entre todos los ciudadanos, tanto de los esfuerzos como de los beneficios económicos, más allá de diferencias étnicas, territoriales, culturales o religiosas. Las respuestas de los encuestados a esta pregunta trilemática podrían variar desde posiciones ideológicas simples y radicales (una, radical en positivo, sería elegir una respuesta al $100 \%$ y rechazar las otras dos; otra, radical 
en negativo, sería rechazar una respuesta al $100 \%$ y elegir las otras dos al 50\%) hasta posiciones ideológicas más complejas (ordenar las tres preferencias en una determinada secuencia, dando a cada preferencia un porcentaje de ponderación que podría ser distinto - no es lo mismo asignar porcentajes de 50-30-20 que 85-10-5 o 45-40-5, incluso en la misma secuencia: el énfasis emocional aquí sería importante-). En todas estas singladuras ideológicas del encuestado, tanto de las más simples y extremas hasta las más complejas, los elementos emocionales presentes jugarían un papel crucial para ver la relación en estas distintas opciones ideológicas. En este sentido, lo que hemos llamado el trilema del trilero no sería otra cosa que el mecanismo emocional que ayuda a elaborar las posibles combinaciones que son fruto del intercambio de los distintos regímenes emocionales inherentes a las tres ideologías.

La primera secuencia sería la posición de aquellos que defienden una especie de igualdad Rpf: una igualdad liberal rawlsianamente razonable aderezada con pequeñas dosis de patriotismo dejando en último término los argumentos fraternales. Este sería, por ejemplo, el modelo trilero que Hayek tenía en la cabeza —en el mejor de los casos- y que, de manera cabal, podemos imaginar como una solución posible de muchas opciones políticas en la mayor parte de los países desarrollados: la opción emocional por una igualdad liberal razonable como guía de conducta pero, si este sentimiento no tiene fuerza, se ofusca o es incomprendido, siempre queda la opción emocional del conservadurismo nacional-patriótico como argumento sentimental de segunda opción, dejando la fraternidad con la opción menos deseable.

La segunda secuencia sería la posición de aquellos que apuestan por una igualdad Rfp: una igualdad liberal básicamente razonable como la anterior, pero que antepondría los argumentos de la igualdad fraternal a la igualdad patriótica. Este sería, por ejemplo, el modelo trilero de Keynes — también, en el mejor de los casos- y que, también de forma cabal, podemos imaginar como una solución que ha servido de ejemplo a muchas opciones políticas de inspiración socialdemocrática, o liberal progresista, que vemos en la mayoría de las democracias liberales (pensemos, sin embargo, hasta qué punto esta secuencia coincide o no con el orden trilemático propuesto por Dani Rodrik en el libro antes citado, cuando señala que la hiperglobalización liberal debería ocupar el tercer lugar de las opciones ideológicas, por detrás de la soberanía nacional de los Estados y la igualdad democrática de los ciudadanos a la hora de tomar decisiones económicas: a pesar de las enormes simpatías de Rodrik hacia Keynes, pensamos que la resolución trilemática entre ambos es ligeramente distinta).

La tercera secuencia posible sería la posición de aquellos que defienden la igualdad Prf: una igualdad de patriotas que son, además, gente razonable, aunque dejarían la fraternidad universal en último lugar: cualquier ciudadano 
nacionalista y/o conservador de cualquier país que, además de amar a sus ciudadanos, tuviera una pequeña dosis de sensatez y pragmatismo podría encajar en este grupo. (Observamos aquí que el trilema del trilero suele tener un arduo trabajo porque muchas veces no es fácil diferenciar esta tercera combinación [la igualdad Prf] de la primera [la igualdad Rpf]: es el problema habitual entre liberales en lo económico que no quieren parecer demasiado nacionalistas o nacionalistas económicos que no quieren parecer demasiado liberales).

Una cuarta secuencia posible sería la posición de aquellos que creen en la igualdad Pfr: una igualdad de patriotas que son fraternales - pueden compartir su igualdad con otras comunidades como forma de expresar su pertenencia a la humanidad, eso sí, tras una consciente observancia igualitaria interna- dejando como última opción la actitud igualitaria razonable. Cualquier nacionalista y/o conservador que, después de amar a sus ciudadanos, entienda que su comunidad puede comprometerse con la igualdad de otras comunidades del mundo a costa de argumentos liberales de razonable apertura económica daría el perfil de este grupo. Aquí suele ocurrir que, ante la ausencia de la actitud razonable, esta pretensión de igualitarismo fraternal internacional suele deslizarse por la pendiente del sesgo comunitario: la igualdad fraternidad suele ejercerse solamente con determinados grupos políticos considerados «aliados», que son como una forma de expandir la propia idea de comunidad nacional fuera de las fronteras de un país. Hayek creía que esta opción, la colusión de sentimientos nacionalistas y socialistas - por este orden- en detrimento del espíritu liberal, era más habitual de lo que se suele pensar y era precisamente la que tenía más posibilidades de poner en peligro el proyecto político liberal.

La quinta secuencia sería la posición de la igualdad Frp: una igualdad fraternal que buscaría apoyarse en actitudes razonables, dejando en último término la igualdad patriótica. Cualquier internacionalista pragmático que piensa en la igualdad económica de la humanidad desde presupuestos emocionales más o menos sensatos sin atender a criterios finalistas de diversidad patriótica podría entrar en este perfil. El principal problema que afronta esta posición es el riesgo de su aislamiento institucional dado que su acción política encuentra una limitación considerable en el marco de los Estados, que es donde se ejerce de forma habitual la dinámica política formal. En la medida que la política no traspasa el umbral de la estatalidad, el sentimiento patriótico que incorpora toda forma de estatalidad bloquea las potencialidades de esta posición.

Finalmente, la sexta secuencia sería la posición de la igualdad Fpr: la igualdad económica basada en criterios de fraternidad democrática universal, uniendo a todas las distintas comunidades patrióticas en busca de condiciones económicas igualitarias más allá de las diferencias individuales y de su 
razonable diversidad. Hay que decir que resulta difícil imaginar en la actualidad un actor político con un grado semejante de incongruencia en su ordenación de preferencias ideológicas. Tal vez esta combinación es la incongruencia por excelencia que demuestra que no todas las combinaciones tienen las mismas posibilidades de realización. Desde el punto de vista lógico todas son iguales, pero si nos atenemos a las emociones políticas, la realidad es que esta última combinación se antoja a día de hoy menos realizable que ninguna.

Creemos, en suma, que este esquema ideológico triangular (liberal $v s$. socialista $v s$. conservadora/nacionalista) y sus correspondientes combinaciones ofrece un marco más adecuado y realista que el propuesto por el eje izquierda-derecha. Aunque esta última dualidad tiene muchos años de recorrido y numerosos estudios avalan su utilidad, existe un volumen importante de trabajos que empiezan a plantear hasta qué punto este esquema ideológico oculta importantes hallazgos sobre cómo funcionan las dinámicas políticas ideológicas (Budge, 2001; Klingemann, 2006). La diferencia entre posiciones emocionales moderadas - centro derecha liberal $v$ s. centro izquierda socialdemócrata- y las posiciones radicales — especialmente, aunque no solo, de la derecha extrema en buena parte de Europa Occidental — ha estado solapada en un marco analítico deficiente que impedía ver las múltiples distorsiones que el nacionalismo/conservadurismo han introducido en el normal funcionamiento del binomio ideológico dual (Kitschelt, 1994; Hooghe et al., 2002; Ignazi, 2003). En este trabajo hemos propuesto un tipo de análisis que podría superar estas deficiencias. Para ello, será preciso aceptar la existencia de una pluralidad ideológica trilemática. Asimismo, hay que aceptar la importancia de las emociones (moderadas o extremas) como un mecanismo que puede ayudar a entender la relación interna entre las ideologías. Finalmente, en tercer lugar, habrá que aceptar que la relación entre las ideologías es muy ambigua y, en ocasiones, es la causa de múltiples incongruencias. Las ideologías son instrumentos válidos para gestionar situaciones políticas complejas, pero también son en muchas ocasiones — de ahí el riesgo y la desconfianza que sufrenherramientas utilizadas políticamente de forma trilera para defender una cosa y hacer otra bien distinta.

\section{Bibliografía}

Alonso, S. y Claro de Fonseca, S. (2012). Immigration, left and right. Party Politics, 18 (6), 865-884. Disponible en: https://doi.org/10.1177/1354068810393265.

Anderson, E. (2015). The fundamental disagreement between luck egalitarians and relational egalitarians. En A. Kaufman (ed.). Distributive justice and access to advantage. G.A. cohen's egalitarianism (pp. 21-39). Cambridge MA: Cambridge University Press. 
Atkinson, A. B. (2015). Inequality. What can be done? Cambridge MA: Harvard University Press. Disponible en: https://doi.org/10.4159/9780674287013.

Avineri, S. y De-Shalit, A. (1992). Communitarianism and individualism. Oxford: Oxford University Press.

Balcells, L. (2007). ¿Es el voto nacionalista un voto de proximidad o un voto de compensación?: una nueva aproximación «espacial» al voto en dos dimensiones. Revista Española de Ciencia Politica, 16, 61-88.

Bobbio, N. (1995). Izquierda y derecha. Razones y significados de una distinción politica. Madrid: Taurus.

Budge, I. (2001). Theory and measurement of party policy positions. En I. Budge, H. Klingemann, A. Volkens, J. Bara y E. Tanenbaum (eds.). Mapping policy preferences. Estimates for parties, electors, and governments 1945-1998 (pp. 75-90). Oxford: Oxford University Press.

Carens, J. (2015). The egalitarian ethos as a social mechanism. En A. Kaufman (ed.). Distributive justice and access to advantage. G.A. Cohen's egalitarianism (pp. 50-78). Cambridge MA: Cambridge University Press.

Casal, P. (2013). Occupational choice and the egalitarian ethos. Economics and Philosophy, 29 (1), 3-20. Disponible en: https://doi.org/10.1017/S0266267113000059.

Cohen, G. A. (1989). On the currency of egalitarian justice. Ethics, 99, 906-944. Disponible en: https://doi.org/10.1086/293126.

- (1990). Equality of what? On welfare, goods and capabilities. Recherches Economiques, 56, 357-383.

- (2000). If You're an egalitarian, how come You're so rich? Cambridge, MA: Harvard University Press.

- (2008). Rescuing justice and equality. Cambridge MA: Harvard University Press. Disponible en: https://doi.org/10.4159/9780674029651.

— (2009). Why not socialism? Princeton, NJ: Princeton University Press.

- (2011). On the currency of egalitarian justice and other essays in political philosophy. Princeton NJ: Princeton University Press.

- (2012). Finding oneself in the other. Princeton NJ: Princeton University Press. Disponible en: ttps://doi.org/10.1515/9781400845323.

- (2013). Lectures on the history of moral and political philosophy. Princeton NJ: Princeton University Press.

Cutts, D. y Goodwin, M. J. (2014). Getting out the right-wing extremist vote: Extreme right party support and campaign effects at a recent british general election. European Political Science Review, 6 (1), 93-114. Disponible en: https://doi.org/10.1017/ S1755773912000288.

De la Calle, L. (2005). Cuando la proximidad deja de ser importante: modelos espaciales y voto en la política vasca, 1994-2001. Revista Española de Ciencia Política, 12, 21-52.

— , L., Martínez, A. y Orriols, L. (2010). Voting without ideology. Evidence from Spain (1979-2008). Revista Española de Investigaciones Sociológicas, 129, 107-129.

De Sousa, R. (1990). The rationality of emotion. Cambridge, MA: The MIT Press.

Downs, A. (1957 [1992]). Teoría económica de la acción política en una democracia. Diez textos básicos de ciencia politica (pp. 93-111). Barcelona: Ariel. 
Duflo, E. (2012). Repensar la pobreza. un giro radical en la lucha contra la desigualdad. Madrid: Taurus.

Dworkin, R. (1985). A matter of principle. Cambridge, MA: Harvard University Press.

- (2000 [2003]). Virtud soberana. Teoría y práctica de la igualdad. Barcelona: Paidós.

Dyson, S. B. (2009). Cognitive style and foreign policy: Margaret Thatcher's black-and-white thinking. International Political Science Review, 30 (1), 33-48. Disponible en: https:// doi.org/10.1177/0192512108097055.

Evans, E. J. (2013). Thatcher and thatcherism. The making of the contemporary world. London: Routledge.

Fairclough, N. (1989). Language and power. New York: Longmans Green.

Fernández Albertos, J. (2002). Votar en dos dimensiones: el peso del nacionalismo y la ideología en el comportamiento electoral vasco, 1993-2001. Revista Española de Ciencia Política, 6, 153-181.

Freeden, M. (1986). Liberalism divided. A study in british political thought 1914-1939. Oxford: Clarendon Press. Disponible en: https://doi.org/10.1093/0198274327.001.0001.

— (1996). Ideologies and political theory: A conceptual approach. Oxford: Clarendon Press.

- (1998). Is nationalism a distinct ideology? Political Studies, 46 (4), 748-765. Disponible en: https://doi.org/10.1111/1467-9248.00165.

- (2003 [2013]). The political theory of political thinking. The anatomy of a practice. Oxford: Oxford University Press. Disponible en: https://doi.org/10.1093/acprof: oso/9780199568031.001.0001.

Gilens, M. (2012). Affluence and influence. Economic inequality and political power in America. Princeton, NJ: Princeton University Press.

Goodspeed, T. B. (2012). Rethinking the keynesian revolution: Keynes, Hayek, and the Wicksell connection. Oxford: Oxford University Press. Disponible en: https://doi.org/10.1093/ acprof:oso/9780199846658.001.0001.

Gornick, J. C. y Jäntti, M. (2013). Income inequality. Stanford CA: Stanford University Press. Disponible en: https://doi.org/10.11126/stanford/9780804778244.001.0001.

Greiff, P. D. (1989). MacIntyre: Narrativa y tradición. Sistema, 92, 99-116.

Gutmann, A. (1985 [1992]). Communitarian critics of liberalism. En S. Avineri y A. De-Shalit (eds.). Communitarism and individualism (pp. 120-137). Oxford: Oxford University Press.

Hayek, F. A. (1959 [1982]). Por qué no soy un conservador. En F. A. Hayek (ed.). Los fundamentos de la libertad (pp. 514-531). Madrid: Unión Editorial.

Hirose, I. (2015). Egalitarianism. London: Routledge.

Hirschman, A. O. (1977 [2014]). Las pasiones y los intereses. Argumentos políticos en favor del capitalismo previos a su triunfo. Madrid: Capitán Swing.

Hooghe, L., Marks, G. y Wilson, C. J. (2002). Does Left/Right structure party positions on european integration? Comparative Political Studies, 35 (8), 965-989. Disponible en: https://doi.org/10.1177/001041402236310.

Hoover, K. R. (1999). Ideologizing institutions: Laski, Hayek, Keynes and the creation of contemporary politics. Journal of Political Ideologies, 4 (1), 87-115. Disponible en: https://doi.org/10.1080/13569319908420790. 
Ignazi, P. (2003). Extreme right parties in Western Europe. Oxford: Oxford University Press. Disponible en: https://doi.org/10.1093/0198293259.001.0001.

Kaufman, A. (2015). Equality and freedom: Cohen's critique on Sen Alexander Kaufman. En A. Kaufman (ed.). Distributive justice and access to advantage. G.A. Cohen's egalitarianism (pp. 117-130). Cambridge, MA: Cambridge University Press.

Keynes, J. M. (1925 [1988]). ¿ ¿Soy un liberal? En J. M. Keynes (ed.). Ensayos de persuasión (pp. 298-308). Barcelona: Crítica.

Kitschelt, H. (1990). The left-right semantics y the new politics cleavage. Comparative Political Studies, 23 (2), 210-238. Disponible en: https://doi.org/10.1177/00104140 90023002003.

- (1994). The transformation of european social democracy. Cambridge, MA: Cambridge University Press. Disponible en: https://doi.org/10.1017/CBO9780511622014.

- (1995). The radical right in western europe. Ann Arbor: University of Michigan Press.

- (2004). Diversificación y reconfiguración de los sistemas de partidos de las democracias postindustriales. Revista Española de Ciencia Politica, 10, 9-51.

Klingemann, H. (2006). Beyond the left-right dimension: Policy profiles and programmatic coherence of party groupings in the european parliament. En H. Klingemann, A. Volkens, J. L. Bara, I. Budge y M. McDonald (eds.). Mapping policy preferences II. Estimates for parties, electors, and governments in Eastern Europe, European Union, and OECD 1990-2003 (pp. 28-50). Oxford: Oxford University Press.

Knight, K. (2006). Transformations of the concept of ideology in the twentieth century. American Political Science Review, 100 (4), 619-626. Disponible en: https://doi.org/10.1017/ S0003055406062502.

- (2009). Luck egalitarianism. Edinburgh: Edinburgh University Press.

Knight, C. y Stemplowska, Z. (2014). Responsability and distributive justice. Oxford: Oxford University Press.

Knutsen, O. (1997). The partisan and the value-based component of left-right self-placement: A comparative study. International Political Science Review, 18, 191-225. Disponible en: https://doi.org/10.1177/019251297018002005.

- (1998). Expert judgements of the left-right location of political parties: A comparative longitudinal study. West European Politics, 21, 63-94. Disponible en: https://doi. org/10.1080/01402389808425245.

Krause, S. R. (2008). Civil passions. Democratic deliberation and moral sentiment. Princeton, NJ: Princeton University Press.

Lago, I. (2000). Identidades duales y abstención diferencial en las comunidades autónomas: los casos de Cataluña, Galicia y País Vasco. Dereito: Revista Xuridica da Universidade de Santiago de Compostela, 9 (2), 83-103.

Laponce, J. A. (1974). Hirschman's voice and exit model as spatial archetype. Social Science Information, 13 (3), 67-81. Disponible en: https://doi.org/10.1177/053901847401300304.

- (1978). Measuring party preference: The problem of ambivalence. Canadian Journal of Political Science, 11 (1), 139-152. Disponible en: https://doi.org/10.1017/ S0008423900038798.

- (1981). Right and left. The topography of political perceptions. Toronto: University of Toronto Press. 
Lazenby, H. (2010). Giving luck egalitarianism and other-affecting choice. Journal of Political Philosophy, 18 (3), 271-286.

Leonisio, R. y Strijbis, O. (2014). Más allá de la autoubicación: por qué el nacionalismo predice mejor el comportamiento electoral en el País Vasco. Revista Española de Investigaciones Sociológicas, 146, 47-68.

Lipset, S. M. y Rokkan, S. (1967 [1992]). Estructuras de división, sistemas de partidos y alineamientos electorales. Diez textos básicos de ciencia política (pp. 231-273). Barcelona: Ariel.

Llera Ramo, F. J. (2010). ¿¿Hay competición política en el País Vasco? De la identidad plural al choque identitario. Treinta años de elecciones en españa (pp. 105-144). Valencia: Tirant lo Blanch.

MacIntyre, A. (1981 [1988]). Tras la virtud. Barcelona: Crítica.

- (1984). Is patriotism a virtue? En A. MacIntyre (ed.). Lindley lecture (pp. 1-20). Kansas: University of Kansas Press.

(1988 [1994]). Justicia y racionalidad. conceptos v contextos. Barcelona: Ediciones Internacionales Universitarias.

— (1991 [1992]). Tres versiones rivales de la ética. Enciclopedia, genealogía y tradición. Barcelona: Rialp.

Magliulo, A. (2013). Hayek and the great depression of 1929: Did he really change his mind? European Journal of the History of Economic Thought, 23 (1), 31-58. Disponible en: https://doi.org/10.1080/09672567.2013.792373.

Mair, P. (2013 [2015]). Gobernando el vacio. La banalización de la democracia occidental. Madrid: Alianza.

Máiz, R. (2010). The political mind and its other: Rethimking the no place of emotions in modern political theory. En M. Engelken, P. Ibarra y C. Moreno (eds.). Politics and emotions. The Obama phenomenon (pp. 29-70). Heidelberg: Springer-Verlag.

(2015). La teoría política de la igualdad ante la crisis de la época presente. Ponencia presentada en el XII Congreso de la AECPA, Donosti-San Sebastián.

Medina, L. (2015). Izquierda y derecha en españa: un estudio longitudinal y comparado. Madrid: Centro de Investigaciones Sociológicas.

Miller, D. (2015). The incoherence of luck egalitarianism. En A. Kaufman (ed.). Distributive justice and access to advantage. G. A. Cohen's egalitarianism (pp. 131-150). Cambridge, MA: Cambridge University Press.

Mulhall, S. y Swift, A. (1992). El individuo frente a la comunidad. El debate entre liberales y comunitaristas. Madrid: Temas de Hoy.

Nagel, T. (1991). Equality and partiality. New York: Oxford University Preas.

Nozick, R. (1974 [1990]). Anarquía, estado y utopía. México: Fondo de Cultura Económica.

Padró-Solanet, A. y Colomer, J. M. (1992). Espacio político-ideológico y temas de campaña. El ejemplo de las elecciones autonómicas de Cataluña de 1992. Revista de Estudios Políticos, 78, 131-159.

Pallarés, F. (1991). Estado autonómico y sistema de partidos: una aproximación electoral. Revista de Estudios Politicos, 71, 281-324.

Parfit, D. (1997). Equality and priority. Ratio, 10 (3), 202. Disponible en: https://doi. org/10.1111/1467-9329.00041. 
Piketty, T. (2013 [2014]). El capital en el siglo XXI. México: Fondo de Cultura Económica.

Plamper, J. (2014). Historia de las emociones: caminos y retos. Cuadernos de Historia Contemporánea, 36, 17-29.

Rawls, J. (1980 [1986]). El constructivismo kantiano en la teoría moral. En M. A. Rodilla (ed.). Justicia como equidad. Materiales para una teoría de la justicia (pp. 137-184). Madrid: Tecnos.

- (1986). Justicia como equidad. Materiales para una teoría de la justicia. Madrid: Tecnos.

Reddy, W. (2001). The navigation of feeling. A framework for the history of emotions. Cambridge, MA: Cambridge University Press. Disponible en: https://doi.org/10.1017/ CBO9780511512001.

Riker, W. H. (1982). Liberalism against populism. A confrontation between the theory of democracy and the theory of social choice. San Francisco: Freeman.

Rodrik, D. (2012). La paradoja de la globalización. Barcelona: Antoni Bosch.

Roemer, J. E. (1996). Egalitarian perspectives: Essays in philosophical economics. Cambridge, MA: Cambridge University Press.

Rokkan, S. (1980). Territories, centres y peripheries. Toward a geoethnic, geoeconomic, geopolitical model of differentiation within Western Europe. En J. Gottmann (ed.). Centre and periphery. Spatial variation in politics (pp. 163-204). London: Sage.

Sen, A. K. (1992). Inequality reconsidered. Oxford: Oxford University Press.

- (2006). Equality of what? En R. E. Goodin y P. Pettit (eds.). Contemporary political philosophy: An anthology, 2nd edition (pp. 473-483). Oxford: Blackwell Publishers.

Sernau, S. R. (2014). Social inequality in a global age. Thousand Oaks, CA: Sage.

Therborn, G. (2013 [2015]). La desigualdad mata. Madrid: Alianza.

Tilley, J. y Heath, A. (2007). The decline of british national pride. British Journal of Sociology, 58 (4), 661-678. Disponible en: https://doi.org/10.1111/j.1468-4446.2007.00170.x.

Torcal, M. y Medina, L. (2002). Ideología y voto en españa, 1979-2000: los procesos de reconstrucción racional de la identificación ideológica. Revista Española de Ciencia Política, 6, 57-96.

- (2007). La competencia electoral entre PSOE y PP: el peso de los anclajes de ideología, religión y clase. En Elecciones generales 2004 (pp. 275-302). Madrid: Centro de Investigaciones Sociológicas.

Van Parijs, P. (1991 [1993]). ¿Qué es una sociedad justa? Introducción a la práctica de la filosofía política. Barcelona: Ariel.

Wapshott, N. (2011). Keynes versus Hayek. El choque que definió la economía moderna. Barcelona: Deusto. 